\section{Analisa Perbaikan Tanah pada Jalan Tol Sumatera Utara Bagian Selatan dengan Metode Preloading}

\section{Muhammad Afief Ma'ruf ${ }^{1}$ Dhandy Pratama ${ }^{1}$ Muhammad Andra Pranatha ${ }^{1}$ Muflihah Sophia Rafi'atunnisa $^{1}$}

1 Program Studi Teknik Sipil, Universitas Lambung Mangkurat

${ }^{2}$ Program Studi Pendidikan Profesi Insinyur, Universitas Lambung Mangkurat

afief.maruf@ulm.ac.id

\section{Pendahuluan}

Pulau Sumatera merupakan salah satu pulau terbesar di Indonesia yang mengalami peningkatan perekonomian setiap tahunnya. Pertumbuhan ekonomi di Pulau Sumatera memberikan kontribusi terhadap Produk Domestik Bruto (PDB) nasional sebesar 21,36 persen pada triwulan I-2019 (Sumber: Badan Pusat Statistik, 2019). Hal ini menyebabkan kontribusi Pulau Sumatera sangat besar dalam mendukung pertumbuhan ekonomi nasional. Oleh karena itu untuk mempercepat pertumbuhan ekonomi tersebut, Pulau Sumatera memerlukan sarana pendukung berupa sarana transportasi yaitu moda transportasi darat berupa jalan tol.

Di Indonesia banyak tersebar wilayah-wilayah yang memiliki tanah lunak, seperti di wilayah Sumatera. Tanah lunak merupakan tanah kohesif yang terdiri dari sebagian besar butir-butir yang sangat kecil seperti lempung atau lanau. Sifat tanah lunak adalah gaya gesernya kecil, kemampatannya besar, koefisien permeabilitas yang kecil dan mempunyai daya dukug rendah jika dibandingkan dengan tanah lempung lainnya. Tanah lempung lunak secara umum mempunyai sifat-sifat sebagi berikut:

1. Kuat geser rendah

2. Bisa kadar air bertambah, kuat gesernya berkurang

3. Bila struktur tanah terganggu, kuat gesernya berkurang

4. Bila basah bersifat plastis dan mudah mampat

5. Menyusut bila kering dan membang bila basah

6. Memiliki kompresibilitas yang besar

7. Berubah volumenya dengan bertambahnya waktu akibat rangkak pada beban yang konstan

8. Merupakan material kedap air
Paper ini fokus merencanakan perbaikan tanah jalan tol Sumatera Utara bagian Selatan dimana jalan dibangun atas tanah yang sangat lunak dan lapisan pasir lepas sehingga diperlukan perkuatan. Metode yang dipilih pada perencanaan ini adalah metode preloading. Ada beberapa langkah yang harus dilakukan, yaitu memperhitungkan tinggi timbunan yang diperlukan dan tinggi timbunan final yang dikehendaki, membuat metode pelaksanaan pekerjaan untuk dapat mencapai elevasi final, dan melakukan analisis geoteknik untuk menghitung nilai angka keamanan. Dari hasil analisa didapatkan besar timbunan tanah yang diperlukan tanpa penambahan beban preloading adalah sebesar $3,825 \mathrm{~m}$, sedangkan bila diberi tambahan berupa beban preloading tinggi timbunan menjadi $5,825 \mathrm{~m}$. Nilai faktor keamanan rencana yang digunakan adalah 1,2 dengan tinggi kritis timbunan $\left(\mathrm{H}_{\text {safe }}\right)$ adalah $3,57 \mathrm{~m}$. Pemasangan geotekstil woven digunakan untuk memperkuat lereng. Berdasarkan analisa rancangan anggaran biaya untuk proyek perbaikan tanah pada jalan tol tersebut didapatkan total biaya sekitar Rp143.024.588.0oo,(Seratus Empat Puluh Tiga Milyar Dua Puluh Empat Juta Lima Ratus Delapan Puluh Delapan Ribu Rupiah)

Kata kunci: jalan tol, perbaikan tanah, preloading, tinggi kritis

Diajukan: 31 Mei 2020

Direvisi: 5 Juni 2020

Diterima: 15 Juni 2020

Dipublikasikan online: 17 Juni 2020

Menurut Terzaghi tanah lempung kohesif diklasifikasikan sebgai tanah lunak apabila mempunyai daya dukung lebih kecil dari $0,5 \mathrm{~kg} / \mathrm{cm}^{2}$ dan nilai standard penetration test lebih kecil dari $4(\mathrm{~N}-\mathrm{SPT} \leq 4)$. Berdasarkan uji lapangan, tanah lunak secara fisik dapat diremas dengan mudah oleh jari-jari tangan. Menurut Toha (1989), sifat umum tanah lunak adalah memiliki kadar air $80-100 \%$, batas cair $80-110 \%$, batas plastis $30-45 \%$, saat dites sieve analysis, maka butiran yang lolos oleh saringan no 200 akan lebih besar dari $90 \%$ serta memiliki kuat geser $20-40 \mathrm{kN} / \mathrm{m}^{2}$.

Salah satu contoh kasus yang dihadapi adalah proyek jalan tol sepanjang $28 \mathrm{~km}$ yang akan dibangun di Provinsi Sumatera Utara bagian selatan. Proyek pembangunan infrastruktur ini seringkali mendapatkan banyak hambatan, sehingga sulit untuk dilakukan. Beberapa hambatan yang muncul diantaranya adalah sebagian rencana section jalan tol sepanjang 3,50 km (Stasiun $=$ Sta. $0+000$ s.d. Sta. $3+$ $500 \mathrm{~m}$ ) harus dibangun di atas tanah pasir sangat lepas (very loose) sampai sangat padat (very dense), yang terletak di atas atau di antara tanah lanau berlempung dengan konsistensi sangat lunak sampai dengan sangat kaku. Karena apabila ada gempa dikhawatirkan kemungkinan adanya likuifaksi pada tanah pasir lepas tersebut dan penimbunan yang dilaksanakan di atas tanah lunak akan mengalami kegagalan geser dan penurunan yang berlebihan. Ini diakibatkan pada saat pemberian beban pada tanah akan mengakibatkan penurunan seketika diikuti oleh proses konsolidasi.

Belajar dari beberapa kasus sebelumnya, maka perlu dilakukan perencanaan yang baik pada bagian tanah asli dan timbunan diatasnya. Dengan tinggi timbunan badan

Cara mensitasi artikel ini:

Ma'ruf, M.A., Pratama, D., Pranatha, M. A., Rafi'atunnisa, M. S. (2020) Jalan Tol Sumatera Utara Bagian Selatan dengan Metode Preloading. Buletin Profesi Insinyur 3(1) 033-039 
jalan yang bervariasi mulai paling rendah dengan tinggi timbunan jalan rencana 2,0 meter dari muka tanah dasar asli, sampai dengan yang paling tinggi pada oprit jembatan setebal 9,0 meter dari muka tanah dasar asli. Timbunan badan jalan akan berupa timbunan tanah biasa dan timbunan tanah pilihan, dengan timbunan tanah pilihan disyaratkan minimal berada pada lapisan 1,0 meter teratas dari timbunan. Berdasarkan hal-hal tersebut, selanjutnya dilakukan analisa untuk mendesain solusi perencanaan timbunan yang sesuai dengan kondisi di lokasi pembangunan jalan tol Provinsi Sumatera Utara.

Pemilihan metode timbunan dipilih karena metode PVD lebih efektif di lapisan tanah dominan lanau (Kuswanda, 2015), sehingga tidak akan efektif pada tanah dengan lapisan pasir yang dominan. Metode timbunan dan preloading serta efektif dalam meningkatkan kepadatan dan kekakuan lapisan pasir di bawahnya. Prinsip ini serupa dengan metode kolom pasir grouting, sehingga kemungkinan likuifaksi dapat diminimalisir (sumber: Dhani, Noor, 2013). Hal ini karena likuifaksi terjadi pada lapisan pasir yang sangat lepas (very loose) dan jenuh air. Dengan metode timbunan maka dapat mengurani angka pori pasir dan meningkatkan kepadatannya.

\section{Metode}

Data yang digunakan dalam makalah ilmiah ini merupakan data hasil penyelidikan tanah di lapangan dimana data tersebut meliputi hasil penyelidikan lapangan yaitu data tanah Sta. $0+000$ s/d Sta. $3+550 \mathrm{~m}$ berupa data Bor Log dan nilai SPT seperti terlihat pada Gambar 1, serta data uji laboratorium. Dari data tersebut kemudian dilakukan analisa pengolahan data tanah dasar untuk mencari besarnya settlement, dan waktu yang diperlukan untuk konsolidasi tanah dasar. Kemudian dari hasil analisa tersebut, diperoleh tinggi timbunan rencana dan

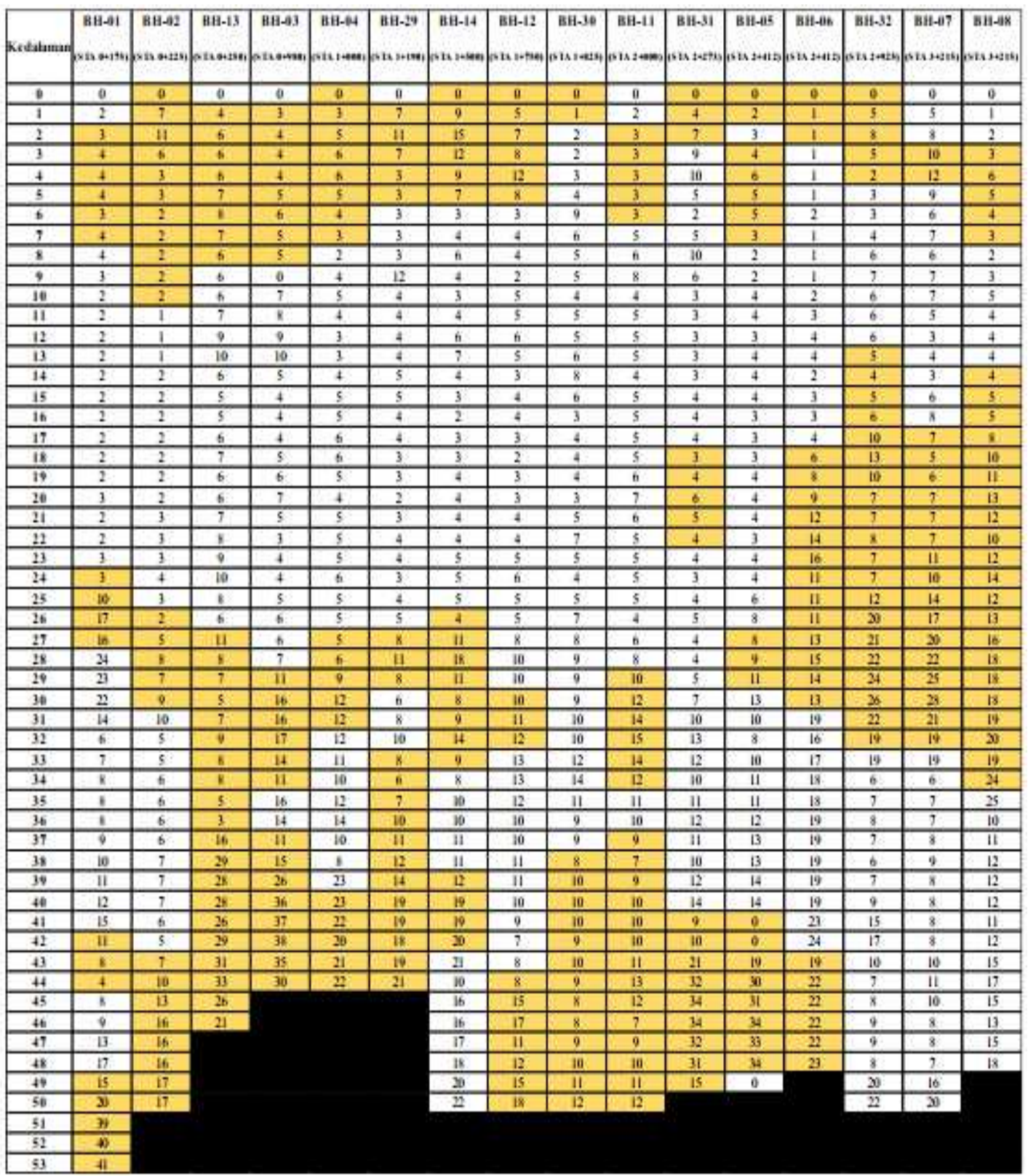

Gambar 1. Bor Log Sta. $0+000$ s/d Sta.3 + 550m 
perhitungan perencanaan perkuatan tanah. Hal tersebut guna untuk menyelesaikan solusi yang baik untuk pelaksanaan timbunan di jalan tol Sumatera

Pada kondisi tanah lunak yang mudah mampat dan tebal, memerlukan pembebanan sebelum pembangunan permanennya dilaksanakan. Ketika beban diletakkan di atas masa tanah, maka akan terjadi proses keluarnya air dari pori-pori tanah. Cara ini disebut pemberian beban awal (preloading). Preloading atau pemberian beban awal dilakukan dengan cara memberikan beban yaitu berupa timbunan sehingga menyebabkan tanah lempung akan termampatkan sebelum konstruksi didirikan (sumber: Hidayati, A.M. dan Ardana, M.D.W. 2008). Maksud dari preloading adalah untuk meniadakan atau mereduksi penurunan konsolidasi primer, yaitu dengan membebani tanah lebih dulu sebelum pelaksanaan bangunannya. Keuntungan dari preloading, kecuali mengurangi penurunan, juga meningkatkan daya dukung tanahnya. Apabila tanah tersebut bukan merupakan jenis tanah yang mudah memampat, tegangan air pori akan berkurang secara perlahan karena air pori hanya dapat mengalir dengan kecepatan yang sangat lambat dengan arah pengaliran vertikal. Apabila kondisi dilapangan seperti itu, maka preloading dilakukan secara bertahap. Adapun prinsip dari metode pra pembebanan (preloading) dan surcharge dapat dilihat pada Gambar 2.

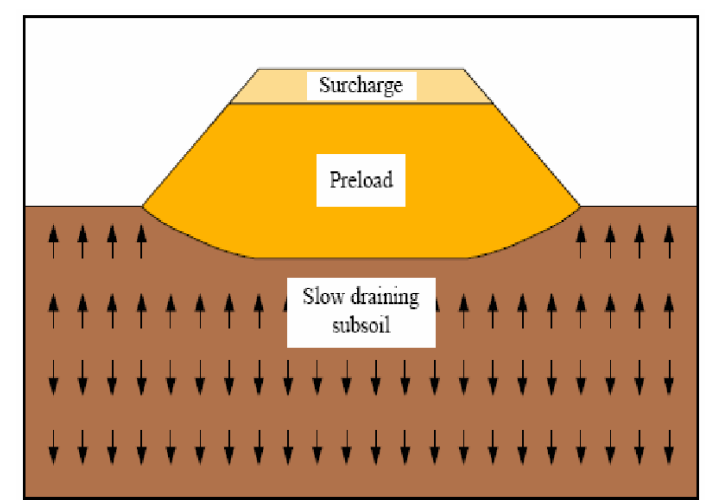

Gambar 2. Prinsip metode pra pembebanan (preloading) dan surcharge

Apabila beban sementara melebihi beban akhir, maka beban tersebut dapat diasumsikan sebagai beban surcharge atau beban jalan. Metode preloading dilakukan dengan cara membiarkan surcharge tersebut dalam beberapa bulan (sebesar 2 s.d. 3 meter lebih tinggi dari rencana elevasi final timbunan) dan nantinya diambil kembali pada waktu (t) tertentu. Secara sederhana, tinggi timbunan preloading + surcharge $\left(\mathrm{H}^{\prime}\right)$ dapat dicari dengan korelasi:

$$
\begin{gathered}
H^{\prime}=H+\Delta H \\
\Delta H=S_{c} \cdot\left(\gamma_{w} / \gamma_{\text {timbunan }}\right)
\end{gathered}
$$

dengan:

$\mathrm{H}=$ tinggi timbunan rencana

$\Delta \mathrm{H}=$ tinggi surcharge

$\mathrm{Sc}=$ total penurunan tanah akibat timbunan $\mathrm{H}$

$\gamma \mathrm{w}=$ berat volume air tawar / air laut

ytimbunan $=$ berat volume material timbunan
Beban sementara bisa dianggap tidak ada apabila pemampatan yang terjadi akibat beban tersebut adalah melebihi pemampatan yang di prediksi. Hal tersebut seharusnya tidak terjadi sebelum nilai excess pore pressure yang tersisa adalah dibawah bertambahnya nilai tegangan akibat pembebanan sementara tersebut. Dengan bertambahnya waktu pembebanan sementara yang berlebih, secondary settlement mungkin bisa berkurang atau bahkan tidak terjadi sama sekali (lihat Gambar 2). Kondisi tersebut disebabkan oleh penggunaan beban surcharge yang lebih besar dari pada beban kerja diatasnya yang dapat menyebabkan tanah bersifat overconsolidated dan nilai secondary compression pada tanah yang bersifat overconsolidated adalah lebih kecil dibandingkan dengan tanah yang bersifat normally consolidated (sumber: Chu dkk 2005).

Metode untuk mendesain tinggi pembebanan yang berhubungan dengan engineering judgement oleh perencana dilakukan dengan prosedur "artificial aging" yang dikembangkan oleh Bjerrum (1972). Penelitian tersebut menitik beratkan pada metode untuk menggunakan desain pre-loading dengan konsep "artificial ageing" yang sudah pernah dilakukan pada beberapa proyek. Konsep ini berhubungan dengan prinsip rangkak (creep), target nilai degree of primary consolidation untuk preloading dan besarnya pemampatan yang diinginkan. Hasil pemampatan tanah yang disebabkan oleh metode preloading dapat dilihat pada Gambar 3.

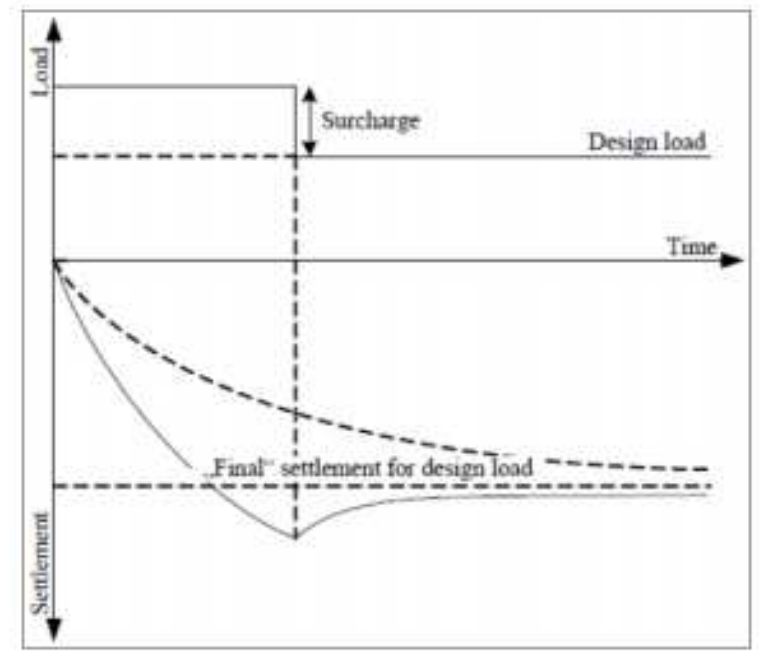

Gambar 3. Grafik Hasil Pemampatan Tanah yang Disebabkan oleh Preloading

\section{Hasil Kerja \\ Penentuan Lapisan Tanah Tipikal}

Pada tahapan awal perencanaan perlu dilakukan penentuan tanah tipikal untuk menentukan karakteristik tiap lapisan tanah. Penentuan tanah tipikal dilakukan sesuai dengan hasil di lapangan dengan menggunakan SPT (Standard Penetration Test). Penyelidikan lapangan menggunakan SPT dilakukan sebanyak 16 titik berbeda dan data laboratorium hasil penyelidikan tanah diambil dari contoh tanah pada lokasi disekitar jalan tol Palindra, Provinsi Sumatera Selatan. Penentuan lapisan tanah dilihat dari keseragaman nilai SPT. Data dianalisa dengan membandingkan jenis tanah dan analisa SPT untuk mendapatkan kedalaman tanah mampu mampat (N-SPT $\leq$ 
10). Data tanah hasil pengeboran dianalisa menggunakan korelasi nilai N-SPT terkoreksi atau tahanan konus untuk mendapatkan konsistensi tanah. Sehingga dapat diketahui bagaimana konsistensi tanah pada lokasi proyek yang digunakan dalam perencanaan. Sedangkan untuk mengetahui sifat-sifat dasar tanah pada sampel bor mesin yang dianalisa menggunakan korelasi dari hasil bor log dan nilai N-SPT dengan Karakteristik Tanah Lainnya (Sumber: J. E. Bowles, 1984 dalam wahyudi, 1999). Titik BH-30 diambil untuk keperluan desain karena memilki kekuatan terendah dengan kedalaman tanah lunak yang paling dalam. Untuk lebih rincinya bagaimana konsistensi tanah pada titik $\mathrm{BH}-30$ dapat dilihat pada Tabel 1.

\section{Penentuan Parameter Tanah}

Berdasarkan hasil pengujian laboratorium terhadap sampel tanah pada lokasi jalan tol Palindra diketahui memiliki kadar air rata - rata $(\omega)$ yang sangat tinggi yaitu $86,62 \%$ dengan derajat kejenuhan $96,13 \%$, berat jenis 2,54 , berat isi basah 1,45 t/m³ , dan berat isi kering 0,785 t/m3. Sedangkan angka pori (e) dan tingkat porositas (n) hasil pengujian menunjukkan 2,24 dan 69,135\%. Berdasarkan hasil tersebut dapat diketahui kondisi tanah dalam keadaan mendekati jenuh sempurna yang dikarenakan tinggi muka air pada titik yang ditinjau adalah $1 \mathrm{~m}$ di bawah permukaan tanah. Hasil pengujian laboratorium terhadap indeks properties tanah dapat dilihat pada Tabel 2.

Tabel 1 Korelasi N-SPT untuk Titik BH-30

\begin{tabular}{lllll}
\hline Kedalaman & $h$ & $\mathrm{~N}-\mathrm{SPT}$ & $\gamma$ & $\begin{array}{l}\text { Konsistensi } \\
\text { Tanah }\end{array}$ \\
\hline$(\mathrm{m})$ & $(\mathrm{m})$ & $\left(\mathrm{t} / \mathrm{m}^{3}\right)$ & & \\
\hline $0-25$ & 25 & $4-6$ & 1,8 & Soft clay \\
\hline $25-37$ & 12 & $6-15$ & 1,8 & Medium clay \\
\hline $37-48$ & 11 & $4-10$ & 1,6 & Loose sand \\
\hline $48-50$ & 2 & $11-30$ & 1,8 & $\begin{array}{l}\text { Medium } \\
\text { sand }\end{array}$ \\
\hline
\end{tabular}

Tabel 2 Hasil Pengujian Laboratorium

\begin{tabular}{llll}
\hline No. & Indeks Properties & Unit & Nilai \\
\hline 1. & Kadar Air $(\omega)$ & $\%$ & 86,62 \\
\hline 2. & Derajat Kejenuhan $(\mathrm{Sr})$ & $\%$ & 96,13 \\
\hline 3. & Berat Jenis $(\mathrm{Gs})$ & - & 2,54 \\
\hline 4. & Berat isi basah $(\gamma \mathrm{n})$ & $\mathrm{t} / \mathrm{m}^{3}$ & 1,45 \\
\hline 5. & Berat isi kering $(\gamma \mathrm{d})$ & $\mathrm{t} / \mathrm{m}^{3}$ & 0,785 \\
\hline 6. & Angka pori $(e)$ & - & 2,24 \\
\hline 7. & Porositas $(n)$ & $\%$ & 69,135 \\
\hline
\end{tabular}

Sedangkan hasil pengujian distribusi ukuran butiran yaitu melalui uji Analisa saringan dan hidrometer, menunjukkan bahwa 99,72\% butiran tanah lolos diameter saringan 0,075 $\mathrm{mm}$ dengan koefisien keseragaman $\left(\mathrm{C}_{\mathrm{u}}\right)$ dan koefisien kelengkungan $\left(C_{c}\right)$ adalah 1,5 dan 16,67 pada kedalaman 3 $\mathrm{m}$ di bawah permukaan tanah. Dari hasil pengujian Oedometer juga diketahui besar angka pori awal sebelum pengujian $\left(e_{0}\right)$ 1,778 pada kedalaman $3 \mathrm{~m}$ di bawah permukaan tanah, koefisien pemampatan $(C C)$ dan koefisien konsolidasi $\left(C_{v}\right)$ sebesar 0,88 dan 0,0642 $\mathrm{cm}_{2} /$ detik. Sedangkan koefisien permeabilitas 7,08 x 10-6 $\mathrm{cm} /$ detik dan koefisien perubahan volume $(m v)$ 0,049 $\mathrm{cm}^{2} / \mathrm{kg}$.

\section{Perencanaan Tinggi Timbunan}

Material timbunan yang digunakan dalam perencanaan ini mempunyai $\gamma_{\text {timbunan }}=2,0 \mathrm{t} / \mathrm{m}^{3}, \gamma_{\text {sat timb }}=2,0 \mathrm{t} / \mathrm{m}^{3}, c_{u}=0$, dan $\phi=30^{\circ}$. Struktur timbunan yang direncanakan pada jalan tol di Sumatera Utara adalah sebagai berikut:

Lebar timbunan $=30$ meter

Kemiringan timbunan $=1: 2$

Tinggi timbunan $=2$ meter

Gambar potongan melintang perencanaan jalan dapat dilihat pada Gambar 4.

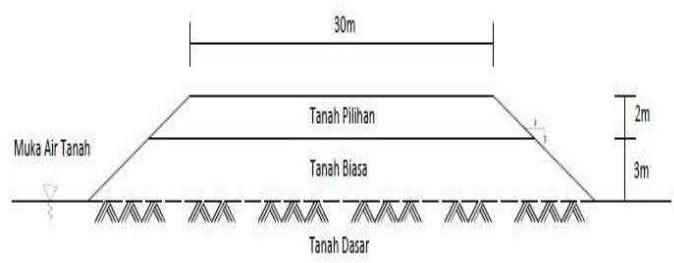

Gambar 4. Rencana Timbunan

\section{Perhitungan Penurunan Konsolidasi}

Pada analisa ini tanah dianggap mengalami Normally Consolidated, sehingga rumus yang digunakan untuk menghitung besarnya penurunan konsolidasi primer adalah sebagai berikut:

$$
S_{c}=\frac{C_{c} H}{1+e_{0}} \log \left(\frac{\sigma_{0}^{\prime}+\Delta \sigma}{\sigma_{0}{ }^{\prime}}\right)
$$

Berikut rekapitulasi nilai Sc yang terjadi secara kumulatif dapat dilihat pada Tabel 3.

Tabel 3. Rekapitulasi Nilai Sc

\begin{tabular}{lll}
\hline $\mathbf{H}$ initial $(\mathbf{m})$ & $\mathbf{S c}(\mathbf{m})$ & $\mathbf{H}$ final $(\mathbf{m})$ \\
\hline 2 & 1,811 & 0,189 \\
\hline 3 & 1,819 & 1,181 \\
\hline 4 & 1,827 & 2,173 \\
\hline 5 & 1,834 & 3,166 \\
\hline 6 & 1,841 & 4,159 \\
\hline 7 & 1,847 & 5,153 \\
\hline 8 & 1,853 & 6,147 \\
\hline 9 & 1,859 & 7,141 \\
\hline
\end{tabular}

Dari tabel diatas dapat dibuat hubungan antara $\mathrm{H}$ final (tinggi timbunan rencana) dengan $\mathrm{H}$ initial (tinggi timbunan awal) seperti terlihat pada Tabel 4.

Tabel 4. Perencanaan Timbunan

\begin{tabular}{lll}
\hline H-Final $(\mathbf{m})$ & H-Initial $(\mathbf{m})$ & Sc $(\mathbf{m})$ \\
\hline 2 & 3,825 & 1,825 \\
\hline 3 & 4,832 & 1,832 \\
\hline 4 & 5,839 & 1,839 \\
\hline 5 & 6,845 & 1,845 \\
\hline 6 & 7,852 & 1,852 \\
\hline 7 & 8,859 & 1,859 \\
\hline 8 & 9,866 & 1,866 \\
\hline 9 & 10,873 & 1,873 \\
\hline
\end{tabular}

\section{Perhitungan Tinggi Kritis Timbunan}

Dalam pelaksanaan di lapangan, timbunan biasa diberikan secara bertahap untuk menghindari kegagalan daya dukung tanah dasar maupun untuk mengurangi bahaya longsor 
pada lereng di ujung-unjung timbunan. Untuk permasalahan ini parameter tinggi kritis timbunan factor keamanan daya dukung tanah dan factor keamanan lereng harus diperhitungkan secara akurat untuk menghindari kegagalan di tengah proses perbaikan tanah dengan metode pemberian beban timbunan. Untuk menghitung tinggi kritis timbunan pendekatan yang digunakan adalah pendekatan yang memiliki kaitan erat dengan konsep kuat geser tanah. Dalam analisa ini digunakan nilai FS sebesar 1,2, dengan nilai Nc 5,14 (berdasarkan tabel Vesic's bearing capacity factors), sehingga persamaannya menjadi:

H safe $=N c . C u S F \cdot \gamma$

Dengan nilai: $C_{u}=16,67 \mathrm{kN} / \mathrm{m} 2$ dan $\gamma=20 \mathrm{kN} / \mathrm{m} 3$

sehingga diperoleh nilai $\mathrm{H}$ safe $(3,57 \mathrm{~m})$ lebih kecil dari besar $\mathrm{H}$ initial $(3,825 \mathrm{~m})$ sehingga perlu

dilakukan penimbunan secara bertahap, namun dengan mengasumsi bahwa tanah mengalami konsolidasi dua arah dimana tanah yang mengalami konsolidasi haruslah homogen dan isotropik sehingga parameter tanah dasar tidak mengalami kenaikan.

\section{Perhitungan Waktu Konsolidasi}

Dilakukan perhitungan waktu penurunan konsolidasi dengan persamaan berikut:

$$
t=\frac{T_{90 \%}\left(H_{d r}\right)^{2}}{C v}
$$

Harga nilai $C_{v}=0,0642 \mathrm{~cm} 2 /$ detik $=202,461 \mathrm{~m} 2 /$ tahun. Maka waktu konsolidasi adalah 5,73 tahun. Berdasarkan analisa di atas dapat diketahui bahwa ketika tanah mengalami konsolidasi mencapai $90 \%$ maka waktu yang dibutuhkan dalam konsolidasi tersebut adalah 5,73 tahun.

\section{Perhitungan Tinggi Kritis untuk Perkuatan Timbunan}

Dari hasil analisa didapatkan besar timbunan tanah yang diperlukan tanpa penambahan beban preloading adalah sebesar 3,825 m, sedangkan bila diberi tambahan berupa beban preloading selama masa pekerjaan konstruksi, tinggi timbunan menjadi 5,825 m. Nilai faktor keamanan rencana yang digunakan adalah 1,25 dengan tinggi kritis timbunan (Hsafe) adalah 3,57 m. Pemasangan geotekstil woven digunakan untuk memperkuat lereng. Untuk mendapatkan $\mathrm{H}$ final $=9 \mathrm{~m}$ adalah $\mathrm{H}$ initial $=10,873 \mathrm{~m}$, berdasarkan perencanaan panjang jalan tol yang harus diperbaiki yaitu sepanjang $L=3,5 \mathrm{~km}=3500 \mathrm{~m}$. Dengan asumsi lebar tanah dasar adalah $\mathrm{b}=50 \mathrm{~m}$ dan perhitungan sebelumnya didapatkan $\mathrm{H}$ safe $=3,57 \mathrm{~m}$ maka direncanakan geotekstil diletakkan kurang dari $\mathrm{H}$ safe $=3,57 \mathrm{~m}$ yaitu setinggi 10,873 $\mathrm{m} / 4=2,72 \mathrm{~m}$. Maka geotekstil diletakkan setiap ketinggian 2,72 $\mathrm{m}$ dan untuk lengan geotekstil diambil $5 \mathrm{~m}$. Desain lebih detail dapat dilihat pada Gambar 5 .

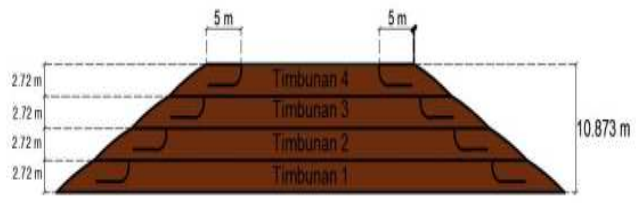

Gambar 5. Sketsa Perkuatan dengan Timbunan

Dengan ini dilakukan perhitungan volume geotekstil yang dipakai untuk perbaikan, dapat dihitung dengan rumus sebagai berikut: Volume geotekstil $=1 / 2(30+50) \times 10,873 \times$ $3500=1.522 .220 \mathrm{~m}$

\section{Perhitungan Rencana Anggaran Biaya}

Untuk daftar kuantitas dan harga yang ditawarkan pada pekerjaan jalan tol Sumatera dapat dilihat pada Tabel 5 . Berdasarkan perhitungan dari perencanaan anggaran biaya d iatas, didapatkan total biaya yang diperlukan untuk proyek perbaikan jalan tol Sumatera sepanjang

$3500 \mathrm{~m}$ adalah senilai Rp143.024.588.000,- (Seratus Empat Puluh Tiga Milyar Dua Puluh Empat Juta Lima Ratus Delapan Puluh Delapan Ribu Rupiah).

\section{Kesimpulan}

Dari hasil analisa didapatkan besar timbunan tanah yang diperlukan tanpa penambahan beban preloading adalah sebesar 3,825 m, sedangkan bila diberi tambahan berupa beban preloading tinggi timbunan menjadi 5,825 m. Nilai faktor keamanan rencana yang digunakan adalah 1,2 dengan tinggi kritis timbunan ( $\mathrm{H}$ safe) adalah $3,57 \mathrm{~m}$. Pemasangan geotekstil woven digunakan untuk memperkuat lereng. Berdasarkan analisa rancangan anggaran biaya untuk proyek perbaikan tanah pada jalan tol tersebut didapatkan total biaya sekitar Rp143.024.588.000,- (Seratus Empat Puluh Tiga Milyar Dua Puluh Empat Juta Lima Ratus Delapan Puluh Delapan Ribu Rupiah.

\section{Ucapan Terimakasih}

Ucapan terimakasih kami berikan kepada Fakultas Teknik Universitas Lambung Mangkurat yang telah banyak membantu terlaksananya penelitian ini.

Tabel 5 Kuantitas dan perencanaan anggaran biaya

\begin{tabular}{|c|c|c|c|c|}
\hline Uraian Kegiatan & $\begin{array}{l}\text { Perkiraan } \\
\text { Kuantitas }\end{array}$ & Satuan & Satuan Harga & Harga \\
\hline \multicolumn{5}{|c|}{ PEKERJAAN TANAH } \\
\hline \multicolumn{5}{|c|}{ Pembersihan Lapangan dan Perataan Tanah } \\
\hline & 1.522 .220 & $\mathrm{~m}^{3}$ & Rp7.000 & Rp10.655.540.000 \\
\hline & 1.522 .220 & $m^{3}$ & Rp70.400 & Rp107.164.288.000 \\
\hline \multicolumn{5}{|c|}{ Pemasangan Geotekstil Woven } \\
\hline & 229.040 & $m^{2}$ & Rp17.000 & Rp3.893.680.000 \\
\hline \multicolumn{5}{|c|}{ Pekerjaan Preloading } \\
\hline & 1.522 .220 & $\mathrm{~m}^{3}$ & Rp14.000 & Rp21.311.080.000 \\
\hline
\end{tabular}




\section{Referensi}

Badan Pusat Statistik (2019). Pertumbuhan Ekonomi Indonesia Triwulan I-2019. No. 39/05/Th.XXII, 6 Mei 2019

Bjerrum et al., 1972. Bjerrum L., Clausen C.J.F., Duncan J.M.General Report to Session IIla: Stability of flexible structures. Proc. Eur. Conf. Soil Mech. Found.

Bowles, J. (1984). Sifat-Sifat Fisis dan Geoteknis Tanah (Mekanika Tanah). Edisi. Kedua. Erlangga. Jakarta

Chu, J. and Yan, S.W. (2005), Application of Vacuum Preloading Method in Soil Improvement Project. Case Histories Book, Edited by Indraratna, B. And Chu, J. Elsevier, London, Vol.3: 91-118.

Dhani, Noor (2013). Karakteristik Kolom Pasir Grouting Sebagai Metode Perkuatan Tanah Lempung Kepasiran. Tesis. Program Pascasarjana Program Studi Magister Teknik Sipil Fakultas Teknik Universitas Hasanuddin Makassar
Hidayati, A.M. dan Ardana, M.D.W. (2008). Kombinasi Preloading Dan Penggunaan Pre-Fabricated Vertical Drains Untuk Mempercepat Konsolidasi Tanah Lempung Lunak (Studi Kasus Tanah Lempung Suwung Kangin). Jurnal IImiah Teknik Sipil Vol. 12, No. 2, Juli 2008

Kuswanda, W. P. (2015). Prosiding Semnas T. Sipil Unlam "Pembangunan Berkelanjutan di Lahan Basah" 16-17 Oktober 2015. Universitas Lambung Mangkurat

Terzaghi, K. and Peck, R. (1967) Soil Mechanics in Engineering Practice. 2nd Edition, John Wiley, New York.

Toha, F. X. 1989. Karakteristik Konsolidasi Lempung Lunak Banjarmasin. National Symposium on Soft Soil and Landslides. HATTI. Bandung

Wahyudi, H., (1999). Daya Dukung Pondasi Dalam. Institut Teknologi Sepuluh November 